
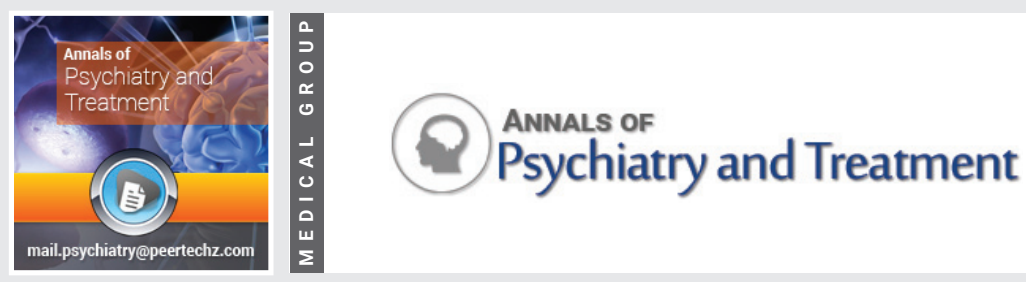

Research article

\title{
Professionalism in patient care: Patient's rights and ethics in the United States of America (USA)
}

Received: 02 June, 2020

Accepted: 12 June, 2020

Published: 13 June, 2020

*Corresponding author: Afolami (Fagorala) Omolayo, Department of Molecular and Cell Biology, University of California, Berkeley, USA, Tel: 9256986890;

E-mail: afolamiomolayo@gmail.com

Keywords: Professionalism; Rights; Ethics; Medicine; Mental Health

https://www.peertechz.com

\section{Check for updates}

\author{
Afolami (Fagorala) Omolayo* \\ Department of Molecular and Cell Biology, University of California, Berkeley, USA
}

\section{Abstract}

Introduction: Professionalism as one of the core competencies in health care service is addressed from a patient's point of view. This paper covers the rights of patients and the ethical obligations of health care workers to ensure patient's satisfaction.

Methods: This research is of a short span and an opportunity to bring about a change in the health care institutions across the nation. Hand written documentations, and patient's daily notes were used to gather information in this article. Internet searches based on medical publications were also used to support this article.

Results: Unprofessional behaviors displayed signified infringement of patient's rights. For instance, false statements on routine court order to ensure mandatory medication use. Disregarding the dangers accompanying such actions. With professionalism overlooked, the normal became verbal abuse and false claims on patient's daily notes in order to justify prolonged hospital stay and wasteful use of health funds.

With reports made to the ethics and grievance committee, patient was given a little bit more audience. However, certain privacy rights were still ignored. Professionals that verbally abused patient were still kept on ward with minimal change to their invading of patient's privacy.

Conclusion: Regular meetings by the board of ethics and grievance committee, which reviews these institutions and their actions regarding abuse of patients' rights, are necessary. Documentations of actions taken by the committee are essential to cause feasible changes that ensure quality of human life. Research has shown that lack of prompt response to unethical or unprofessional behavior as observed in the institution addressed in this paper leads to more professionals mirroring these unprofessional behaviors as if they were normal and patients left to bear the brunt. Thereby creating poor well-being of patients' and the health care system.

\section{Introduction}

Medicine and the skills in patient care are topics crucial for patient satisfaction and full recovery. Amidst a pandemic, uncomfortable flaws in the care of patients at medical institutions of higher learning in the USA have been a neglected subject. From a patient's perspective, I wish to describe an experience that addresses the main subject matter of this paper. The use of the word "personnel" instead of "professionals" in this paper show the deviation from the guidelines necessary to uphold the title "professionals". This paper will mostly be addressed in first person with the location in Chicago, Illinois.

Chicago is a major city with a history of medicine that spans several decades and reflects what other parts of the nation upholds in the field of medicine. It is my hope that this article causes a positive change in the health care system and in the overall well being of patients in the future.

I consider my experience an eye-opener. I completed the last major medical education years - clinical clerkship years working along side licensed professionals in varied medical fields. With daily observance of patients' rights and professionalism upheld, this has built my interests in the field of medicine and has been the foremost priority in patient care.

As a patient, it was a surprise to be placed in a clinical setting that lacked professionalism in patient care albeit this is the same national health care system where I had attended to and observed the opposite during my educational training. I 
had to document this experience in a paper and raise awareness to the abuse of patients' rights and ethics.

Professionalism is defined as the means by which employers and employees abide by certain guidelines that ensure cordial relations with their consumers.

The Accreditation Council for Graduate Medical Education (ACGME) defines professionalism as one of the core competencies mandatory for medical practice. It is the expectation for medical professionals to treat all people with respect, compassion and dignity and for patients' needs to supersede self-interest [1].

The American board of Internal Medicine (ABIM) foundation further based this definition on certain criteria and commitments to:

-Competency - Confidentiality - Appropriate patient relations

-Quality care improvement - Improving access to care - unbiased finite resource distribution - Scientific knowledge - Managing conflict of interest and maintaining trust -Professional responsibilities [2].

Several boards of medical education and practicing physicians have defined professionalism as the observance of certain "attributes, behaviors, commitments, values and goals" that make up a profession and its members are regarded as professionals [3-5].

The observance of professionalism has gained patient satisfaction and improved treatment plans and adherence. This paper will be discussing the necessity for professionalism and actions taken with a lack thereof in order to improve patients' rights and trust in our health care system.

\section{Methods}

University of Illinois (UIC), Chicago board of ethics and grievance committee have been informed of my grievances and are aware of further actions that can be taken should patient satisfaction be breached the way it was at their hospitals [6]

Evaluation of complaints provided to the UIC Ethics and Grievance team support the patient's experience as described in this paper.

This paper covers a span of six to seven weeks of detainment in a locked in adult psychiatry unit of UIC while pregnant. Hand written daily notes of patient's experience was documented from the time of admission till discharge. The medical personnels' daily notes were also provided at the end of patient's care. Excerpts from both daily notes were reviewed and they give a balanced view on the main theme of this paper (See Figures and Documentation) $[6,7]$.

Internet searches on "PROFESSIONALISM", "PROFESSIONALISM IN MEDICINE", "DEFINE PROFESSIONALISM"; PubMed and NEJM Knowledge+ were also used in this paper for understanding the core competencies of Medical practice.

\section{Results}

Patient's rights were infringed upon by several claims of patient's health history without permission and proof of informant. Physicians who were given the highest responsibilities on the hospital unit made several false claims on patients' health history and collegial knowledge of patient's history without permission or approval of such information. Derogatory statements such as "You can bite your nails" or "Pee on the floor" were statements made by the personnels; Doctors and nurses do not uphold the code of ethics and guidelines for their practice.

Several meetings with the patient led to instances with forgetful personnels who guessed on main diagnoses and presented contradictory documentations. Copies in patient's records show involuntary and voluntary admission on to the unit all at once, which should not be. Accompanied by court mandated medication use based on involuntary admission. However, several conditions differentiate an involuntary patient from a voluntary one. The personnels refuse to observe these differentiations and chose whatever was convenient to self (self-interest) while ignoring patient's rights (i.e. neglecting patients' interests and "first do no harm") and harboring wrong documentations.

Several omissions and portrayal of unprofessionalism signify the lack of observance of the code of medical practice at this institution without remorse.

Erratic medication use and lack of titration adds to the lack of professionalism observed during the stay at this unit. In spite of any medication side effects, patient's fetus was not given any regard nor was emotional connection shown by the personnels towards patient's vulnerable state.

The physicians also intended to move to even more dangerous medications such as lithium, which are, regarded as class $\mathrm{C}$ or D drugs and which are detrimental to both patient and fetus' health, it is obvious to see where the guidelines of professionalism and compassion towards human life was lost under falsely acquired court mandated medication use order and self interests.

On several occasions, nurses have mentioned or shown in the patient's notes the aim to "watch their backs" rather than putting the patient's interest first. Nurses noted claims on notes of meditation or quiet time as abnormal behaviors.

Derogatory statements and verbal abuse of patient became the norm and was only lessened with patient's complaints to the ethics and grievances' committee, albeit these complaints were only successful due to patient being conscious, less medicated and cognitively sound to make these important decisions.

\section{Discussions}

Within this prolonged hospital stay and presence of vulnerable patients during a pandemic, mentions of "watching our backs", " to protect self interests" became the language of 
nurses and doctors proving ignorance of the Hippocratic oath and professionalism. Thus the field is turned into a trade rather than a self-sacrificial calling that it was meant to be.

Patients' legally binding notes included false claims to supposedly "cover the backs" of the doctors and nurses and to encourage rouge methods of patient's care; by investigating, taking the patient out of the picture and routine assumption to fit the diagnosis they hoped for.

Patient's vulnerability was ignored with physicians' false claims and unprofessional behaviors through out stay. For instance, several pneumonia patients were admitted and within close proximity of a pregnant patient and the COVID-19 infected patients were said to have filled a floor in the same hospital with spillovers of such patients on the same unit as a pregnant patient. Use of Personal Protective Equipment (PPE) was honored only at the request of the patient and taken seriously only when deaths were being accounted for on the news and the dangers of this virus becoming apparent, else patient was noted as "paranoid" "guarded" at the expression of fears or dangers of being vulnerable and exposing a fetus to potential dangers and medication side effects. Personnels remained "self interest" focused.

Attempts at discharge were blocked with excuses and prolongation of hospital stay with erratic medication use to enhance silencing the patient. Rouge investigations of situations surrounding patient's admissions with claims on history of presenting illness were the norm. It became essential that patient kept documentations of these false claims which had been presented to the court.

This article is written with the hope that information gathered from this experience would bring about the awareness and open more platforms for discussions on the topics of unprofessionalism and its effects to patients' morale and the health care system in the USA.

\section{Conclusions}

The tools for evaluating professionalism are widely available and essential to the improvement of professionalism. Regular reviews by the appropriate board or committee in health institutions should be mandatory and the product of these meetings should not be ignored.

Research has shown that much of the training years of medical professionals had to involve regular evaluation of core competencies for practice, which include professionalism. Improvements have only been observed when steps are made to correct the lapses in professionalism [3]. Quality of life of patients have also seen improvements when their voices are not silenced and when they are given the care promised in the Hippocratic oath.

Although at UIC, there existed an ethics and grievance team that recorded reports made by patients, there was no addressing or acknowledgement of patient's reports or suffering. For instance, with verbal abuse no formal apology was made to the patient. Personnels also remained bold and persisted in the practice of falsely accusing patient in order to save their jobs. Hence giving the impression that the norm has been full proof and patients' complaints should always be ignored. This leads to fear, frustrations and stressful stay at such health facility. Health care facilities should do otherwise, that is, alleviate any fears or frustrations.

More work needs to be done on the part of the evaluating review board. 360-assessment tools [3,5], which would bring all working professionals in each institution together for regular meetings, should be used. This would hold them accountable to documents signed, care given and statements uttered. Videos of the units were taken during this experience as well. There is no knowledge of how these videos were used. It would be to the advantage of a healthy institution and to the improvement of the review board that these videos and audios be evaluated should unprofessional behavior be witnessed or reported.

Publications and reports on the outcome of regular evaluations should be made available to the public. This will help improve the quality of care and enhance the behaviors of the members observing these core competencies necessary to fulfill their title: professionals. The health care system in the United States once an envy of the world would once again regain its position if these evaluations are taken seriously and reasonable consequences for lapses are noted. Thereby improving patients' care and the credibility of the groups of professionals practicing within its borders.

The lack of varied information in supplementation of research online limited the opportunity for a robust literature. For the reports and documentations included in this paper, reporting bias due to inaccurate reported and unreported findings is also a limitation to this paper.

\section{Acknowledgements}

Author thanks all participants for their contribution to this article.

\section{References}

1. New England Journal of Medicine -NEJM Knowledge Link: https://bit ly/2Yrw18t

2. ABIM Foundation. American Board of Internal Medicine; ACP-ASIM Foundation American College of Physicians-American Society of Internal Medicine (2002) European Federation of Internal Medicine Medical professionalism in the new millennium: a physician charter. Ann Intern Med 136: 243-246. Link: https:// bit.ly/3hoGZnE

3. Mueller PS (2015) Teaching and assessing professionalism in medical learners and practicing physicians. Rambam Maimonides Medical Journal 6 : e0011. Link: https://bit.ly/2XZCrwJ

4. Kirk LM (2007) Professionalism in medicine: definitions and considerations for teaching. Proceedings (Baylor University. Medical Center), 20: 13-16. Link: https://bit.ly/2XVbMBg

5. American Board of Pediatrics. Education and Training Committee. Teaching a Promoting and Assessing Professionalism Across the Continuum: A Medical Educator's Guide. Link: https://bit.ly/30EGiR 
6. University of Illinois Health Privacy and Hospital Records Retrieval and Information. Pictorial representation of personnel's notes in Chicago, 2020. Link: https://bit.ly/2COG6BM
7. University of Illinois Health (2020) Ethics and Grievances. Handwritten reports from patient's experience in UIC. Pictorial representation of handwritten reports in Chicago.
Discover a bigger Impact and Visibility of your article publication with

Peertechz Publications

\section{Highlights}

* Signatory publisher of ORCID

* Signatory Publisher of DORA (San Francisco Declaration on Research Assessment)

- Articles archived in worlds' renowned service providers such as Portico, CNKI, AGRIS, TDNet, Base (Bielefeld University Library), CrossRef, Scilit, J-Gate etc.

* Journals indexed in ICMJE, SHERPA/ROMEO, Google Scholar etc.

* OAI-PMH (Open Archives Initiative Protocol for Metadata Harvesting)

* Dedicated Editorial Board for every journal

- Accurate and rapid peer-review process

* Increased citations of published articles through promotions

* Reduced timeline for article publication

Submit your articles and experience a new surge in publication services (https://www.peertechz.com/submission).

Peertechz journals wishes everlasting success in your every endeavours.

Copyright: () 2020 Omolayo A. This is an open-access article distributed under the terms of the Creative Commons Attribution License, which permits unrestricted use distribution, and reproduction in any medium, provided the original author and source are credited.

Citation: Omolayo A (2020) Professionalism in patient care: Patient's rights and ethics in the United States of America (USA). Ann Psychiatry Treatm 4(1): 030-033. DOI: https://dx.doi.org/10.17352/apt.000017 